\title{
The influences of SLCO1B1 and $A B C B 1$ genotypes on the pharmacokinetics of simvastatin, in relation to CYP3A4 inhibition
}

\begin{abstract}
Aim: To investigate the combined effects of SLCO1B1 and $A B C B 1$ genotypes on the pharmacokinetics of simvastatin and its active metabolite simvastatin acid, in relation to CYP3A4 inhibition. Methods: We conducted a single-dose pharmacokinetic study of simvastatin in 26 healthy volunteers screened for their SLCO1B1 C.521T>C and $A B C B 1$ c. $1236 C>T-2677 G>T-3435 C>T$ genotypes, with and without amlodipine pretreatment. The genetic effects and drug-interaction effect on simvastatin pharmacokinetic parameters were analyzed using a linear-mixed model. Results: The SLCO1B1 c.521T>C variant significantly increased exposure to simvastatin acid by around $40 \%(p<0.05)$, similar to that caused by the amlodipine pretreatment. The $A B C B 1$ gene showed no influence on exposure to simvastatin or simvastatin acid. Conclusion: Only SLCO1B1, not $A B C B 1$ genotype, is likely to be associated with simvastatin-induced myopathy. SLCO1B1 genotyping may be particularly beneficial in simvastatin users who are co-administered CYP3A4 inhibitors.
\end{abstract}

First draft submitted: 18 December 2016; Accepted for publication: 7 February 2017; Published online: 28 March 2017

Keywords: $A B C B 1 \bullet$ amlodipine $\bullet$ pharmacogenomics $\bullet$ pharmacokinetics $\bullet$ simvastatin - SLCO1B1

Simvastatin is one of the world's most frequently prescribed drugs due to its excellent hypolipidemic performance and relatively low price as a generic drug. However, simvastatin is known for its higher association with myopathy than other statins [1], and this adverse effect is pharmacokinetics related [2]. The pharmacokinetics of simvastatin is mainly determined by its disposition (i.e., distribution and metabolism) rather than its absorption (which occurs rapidly and almost completely in the GI tract) (Figure 1). Simvastatin, as a prodrug, undergoes extensive metabolism (including first-pass metabolism) to the extent that its absolute bioavailability is less than 5\% [3]. Metabolism, including nonenzymatic reversible hydrolysis into its active metabolite simvastatin acid and enzymatic Phase-I metabolism which is primarily mediated by the CYP enzyme CYP3A4 [4], predominantly takes place in the liver cells.
Distribution (e.g., influx and efflux across the liver cell membrane) of simvastatin is mainly through passive diffusion due to its lipophilic property [5]. Contrastingly, simvastatin acid is hydrophilic and therefore subject to active transport. The influx of simvastatin acid is mainly mediated by the OATP1B1 transporter, which is encoded by the SLCO1B1 gene. Numerous genetic mutations, particularly the SLCO1B1 c.521T>C variant (SNP ID: rs4149056; present in SLCO1B1*5, *15, ${ }^{*} 16$ and ${ }^{*} 17$ haplotypes) have been confirmed to be associated with simvastatin's pharmacokinetics [6] and myopathy [7-9]. On the other hand, it is reported that the efflux of simvastatin acid is mediated by the P-gp transporter [10] which is encoded by the $A B C B 1$ gene, and the c.1236C $>\mathrm{T}-2677 \mathrm{G}>\mathrm{T}(\mathrm{A})-$ 3435C>T (SNP ID: rs1128503, rs2032582 and rs1045642, respectively) haplotype in this gene are associated with simvastatin's
Fen Jiang ${ }^{\ddagger}, 1$, Jong-Yeol Choi ${ }^{\ddagger 1}$, Ju-Hyun Lee', Sunae Ryu' ${ }^{1}$, Ze-Won Park', Jong-Gu Lee', Han-Sung Na', Seok-Yong Lee², Woo-Yong Oh$^{1}$, Myeon-Woo Chung 1 \& Seung-Eun Choi*,1

${ }^{1}$ Clinical Research Division, National Institute of Food \& Drug Safety Evaluation, Ministry of Food \& Drug Safety, Cheongju, Republic of Korea ${ }^{2}$ School of Pharmacy, Sungkyunkwan University, Suwon, Republic of Korea *Author for correspondence:

Tel.: + 82437195251

Fax: +82437195250 choi77@korea.kr

${ }^{\ddagger}$ Authors contributed equally
Future
Medicine
part of 


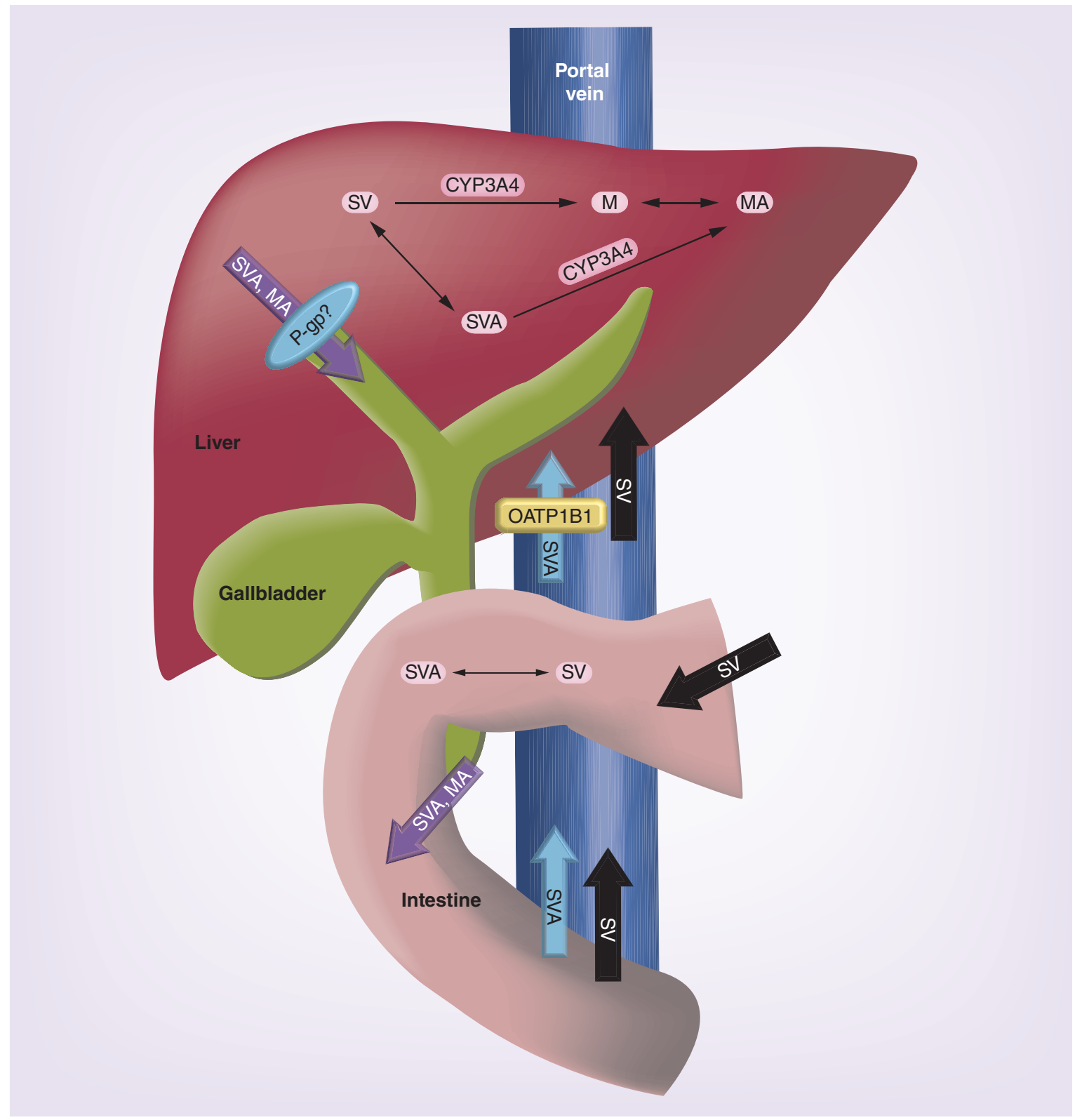

Figure 1. Pathway of simvastatin disposition in the human gastrointestinal system based on previous reports. M: Phase-I metabolites of simvastatin in lactone form; MA: Phase-I metabolites of simvastatin in acid form; SV: Simvastatin; SVA: Simvastatin acid.

pharmacokinetics [11] and adverse reactions [12], but study results have been conflicting [13,14]. Although the effects of $S L C O 1 B 1$ genotype and $A B C B 1$ haplotype on simvastatin disposition have been studied separately or (recently) within one study [14,15], their combined effects on the pharmacokinetics of simvastatin are unknown, particularly with the presence of a CYP3A4 inhibitor. And hence the combined risk of myopathy these factors pose is undetermined.

The primary objective of this study was to determine the influences of the $S L C O 1 B 1$ c. $521 \mathrm{~T}>\mathrm{C}$ variant and the $A B C B 1$ c. $1236 \mathrm{C}>\mathrm{T}-2677 \mathrm{G}>\mathrm{T}-3435 \mathrm{C}>\mathrm{T}$ haplotype on the pharmacokinetics of simvastatin in relation to CYP3A4 inhibition, in healthy volunteers. To analyze the in vivo functions of the minor alleles in both the SLCO1B1 and $A B C B 1$ genes, we adopted a genetic polymorphism enrichment study design. To produce a CYP3A4 inhibitory effect, we pretreated subjects with amlodipine which is a known weak CYP3A4 inhibitor and the most commonly coprescribed calcium-channel blocker with simvastatin [16]. To evaluate the influence of baseline CYP3A4 activity on the genetic effects of interest, we measured and compared all study subjects' CYP3A4 activity using the urinary $6 \beta$-hydroxycortisol/cortisol index that has been adopted in other studies $[17,18]$. 


\section{Methods}

Subject selection based on SLCO1B1-ABCB1 combined genotypes

We genotyped four polymorphic alleles, including the c.521T>C in the $S L C O 1 B 1$ gene, the c.1236C>T, c. $2677 \mathrm{G}>\mathrm{T}$ and the c. $3435 \mathrm{C}>\mathrm{T}$ in the $A B C B 1$ gene, in 489 unrelated Korean individuals. Four combined genotypes were selected as candidate genotypes: T/TCGC/CGC, T/C-CGC/CGC, T/T-TTT/TTT and T/C-TTT/TTT (the T/T and T/C before the dash represent the genotypes of SLCO1B1 c.521T>C; the CGC/CGC and TTT/TTT after the dash represent the haplotypes of $A B C B 1 \quad$ c. $1236 \mathrm{C}>\mathrm{T}-2677 \mathrm{G}>\mathrm{T}-$ $3435 \mathrm{C}>\mathrm{T}$ ). The genotyping methods have been described previously [19-21]. Individuals with the four candidate genotypes were contacted for further screening through physical examination and laboratory tests. It was calculated that a minimum of ten individuals would be required for each SLCO1B1 and ABCB1 genotype group to demonstrate a $30 \%$ difference in simvastatin pharmacokinetic parameters at a level of significance of $\mathrm{p}=0.05$ and power of $80 \%$. In the end, 26 healthy volunteers (T/T-CGC/CGC, $\mathrm{n}=6$; T/TTTT/TTT, $\mathrm{n}=10$; T/C-CGC/CGC, $\mathrm{n}=7$ and T/CTTT/TTT, $n=3$ ) were enrolled into the study. From 1 week prior to commencement and throughout the clinical trial, volunteers abstained from all the drugs and nutritional supplements, tobacco, alcohol, caffeine and grapefruit juice.

\section{Clinical trial}

The clinical trial was a fixed-sequence two-period study, as a substrate $(S)$ period was followed by a substrate + inhibitor $(S+I)$ period. The fixed-sequence design is popularly adopted in drug-drug interaction studies and supported by the US FDA and EMA. In the first period (designated as the control period), all study participants were admitted overnight to the clinical trial center and urine was collected for $12 \mathrm{~h}$ (from $8 \mathrm{PM}$ to $8 \mathrm{AM}$ ). After fasting overnight, at $8 \mathrm{AM}$ each participant received a single oral dose of $40 \mathrm{mg}$ simvastatin (Chong Kun Dang Pharm, Seoul, Republic of Korea) with $240 \mathrm{ml}$ of tap water. Twelve blood samples $(7 \mathrm{ml}$ draw volume of each sample) were collected from each participant via intravenous catheter before and at 0.33 , $0.67,1,1.5,2,3,4,5,7,9$ and $12 \mathrm{~h}$ post drug administration (sampling time was determined based on reported half-life for simvastatin and simvastatin acid which are around $3 \mathrm{~h}$ ). The second period (designated as the amlodipine period) was similar to the first period in design. Following a 7-day washout period, participants took a pretreatment oral dose of $5 \mathrm{mg}$ amlodipine (Ilhwa Co., Ltd, Gyeonggi-Do, Republic of Korea) at 8 AM for three consecutive days. Subject were then admitted and fasted overnight, with urine collected from 8 PM to $8 \mathrm{AM}$. At $8 \mathrm{AM}$, each participant received an oral dose of amlodipine $5 \mathrm{mg}$ together with a single oral dose of $40 \mathrm{mg}$ simvastatin (Chong Kun Dang Pharm). The second period then followed the same procedures as the first. Vital signs and electrocardiograph were monitored during the trial and all adverse reactions were recorded. The study was approved by the Institutional Review Board of the Korean National Institute of Food and Drug Safety Evaluation and carried out in accordance with the Declaration of Helsinki. A written informed consent was obtained from each study participant. The clinical trial was conducted in the Clinical Trial Center of Samsung Hospital, Seoul, Republic of Korea. The Clinical Research Information Service, Republic of Korea (a primary registry in the WHO Registry Network) identifier is KCT0001119.

\section{Drug analysis}

Investigators who conducted the drug analysis were blinded to the subjects' treatments and genotypes. All samples were prepared and analyzed in triplicate, and mean values were used for data analysis. The plasma concentration of simvastatin and its active metabolite simvastatin acid were determined by ACQUITY ultra performance liquid chromatography (UPLC)/Xevo TQ Tandem mass (MS/MS) system (Waters Corp., MA, USA). A total of $0.5 \mathrm{ml}$ of plasma was spiked with $50 \mu \mathrm{l}$ of lovastatin $(0.25 \mathrm{mg} / \mathrm{ml})$ as an internal standard, buffered with $0.2 \mathrm{ml}$ of $0.02 \mathrm{M}$ ammonium formate $(\mathrm{pH}=4.5)$ and extracted with $3 \mathrm{ml}$ of methyl tertiary butyl ether. After centrifugation $\left(4000 \mathrm{rpm}, 4^{\circ} \mathrm{C}\right.$, $5 \mathrm{~min}$ ), the organic phase was evaporated to dryness by a gentle flow of nitrogen heated to $40^{\circ} \mathrm{C}$. The residue was reconstituted in $0.2 \mathrm{ml}$ of reconstitution solvent $(0.1 \%$ formic acid: acetonitrile $=20: 80, \mathrm{v} / \mathrm{v})$ and $5 \mu \mathrm{l}$ of the sample was injected into an LC-MS/MS system. Chromatographic separation of the compounds was accomplished by ACQUITY UPLC BEH C18 Column $(1.7 \mu \mathrm{m}, 2.1 \mathrm{~mm} \times 50 \mathrm{~mm}$, Waters Corp.). For the isocratic mobile phase, a mixture of $0.02 \mathrm{M}$ ammonium formate $(\mathrm{pH}=4.5)$ and acetonitrile was delivered at a flow rate of $0.3 \mathrm{ml} / \mathrm{min}$. MS positive ion mode was chosen. Precursor-to-product ion reactions were monitored for simvastatin, simvastatin acid and lovastatin. The mass-to-charge ratios were 419.32/199.15, $437.3 / 285.2$ and 405.3/199.15, respectively. The lower limits of quantification for simvastatin and simvastatin acid were 0.2 and $0.1 \mathrm{ng} / \mathrm{ml}$, respectively. The interassay variation was less than $20 \%$.

Urinary cortisol and its metabolite $6 \beta$-hydroxycortisol were determined by ACQUITY UPLC/Xevo TQ MS/MS system (Waters Corp.). For each urine sample, $0.25 \mathrm{ml}$ was transferred to an E-P tube and 
then $0.25 \mathrm{ml}$ phosphate-buffered solution and $20 \mu \mathrm{l}$ internal standard ( $6 \alpha$-methylprednisol) was added. After mixing, $50 \mu \mathrm{l}$ of the sample was loaded to an SPE cartridge which was preconditioned and equilibrated with methanol followed by water. The analyte was eluted with $1 \mathrm{ml}$ methanol and the eluate was then evaporated to dryness by a gentle flow of nitrogen heated to $45^{\circ} \mathrm{C}$. The residue was reconstituted in $50 \mu \mathrm{l}$ reconstitution solvent (30\% methanol) and then $5 \mu \mathrm{l}$ of the sample was injected into an LC-MS/MS system. Chromatographic separation of the compounds was accomplished by an ACQUITY UPLC BEH C18 column $(1.7 \mu \mathrm{m}, 2.1 \mathrm{~mm} \times 50 \mathrm{~mm}$, Waters Corp.). The gradient mobile phase consisted of $5 \mathrm{mM}$ ammonium formate $(\mathrm{pH}=3.0)$ and $0.1 \%$ formic acid in acetonitrile delivered at a flow rate of $0.3 \mathrm{ml} / \mathrm{min}$. MS negative ion mode was chosen. For cortisol, $6 \beta$-hydroxycortisol and $6 \alpha$-methylprednisolone, the precursor-to-product ion reactions were monitored and their mass-to-charge ratios were 407.4/331.35, 423.4/347.3 and 419.4/343.3, respectively. The lower limits of quantification for cortisol and $6 \beta$-hydroxycortisol were 2.5 and $10 \mathrm{ng} / \mathrm{ml}$, respectively. The interassay variation was less than $20 \%$.

\section{Data analysis}

Genetic information obtained from the 489 Koreans was tested for linkage disequilibrium using the haplotype analysis software Haploview 4.2 (Broad Institute, MA, USA). The pharmacokinetic parameters of simvastatin and simvastatin acid were derived from plasma concentration data by a noncompartmental method using Phoenix WinNonlin 6.3 (Pharsight Corp., CA, USA). And for statistical analysis, all pharmacokinetic parameters were log-transformed for further analysis. Effects of SLCO1B1 and $A B C B 1$ genotypes and CYP3A4 inhibition, as well as their interactions were analyzed by a linear-mixed model using SPSS software 21.0 (SPSS Inc., IL, USA). The effect of CYP3A4 inhibition was estimated as a repeated variable, the SLCO1B1 and ABCB1 genotypes and CYP3A4 inhibition were set as fixed effects, and subject ID was set as a random effect. The comparison of exposure of simvastatin acid between subjects of the SLCO1B1 c.521T/T genotype in control period and subjects of the SLCO1B1 c.521T/C genotype in amlodipine period was conducted using an independent samples $t$-test. $\mathrm{p}<0.05$ was considered statistically significant.

\section{Results}

SLCO1B1-ABCB1 combined genotypes in 489 unrelated Koreans

A total of 49 SLCO1B1-ABCB1 combined genotypes were identified in 489 unrelated Korean individuals: 23 of the combined genotypes showed a frequency of more than $1 \%$, and the remaining 26 combined genotypes accounted for $9.2 \%$ (Table 1). In the $A B C B 1$ gene, the c.1236C > T, c. $2677 \mathrm{G}>\mathrm{A}(\mathrm{T})$ and c. $3435 \mathrm{C}>\mathrm{T}$ alleles were in strong linkage disequilibrium. However, the SLCO1B1 c.521T>C allele was not linked with any of the three alleles in the $A B C B 1$ gene (data were not shown). Four combined genotypes were chosen for study: the 3rd (T/T-TTT/TTT), the 8th (T/TCGC/CGC), the 14th (T/C-TTT/TTT) and the 18th (T/C-CGC/CGC). Due to difficulty in recruiting individuals with the 18th (T/C-CGC/CGC) genotype, two individuals from the 15 th (T/C-CGC/TGC) genotype were included instead (the two genotypes differed by one $A B C B 1$ c.1236C $>$ T allele).

\section{Baseline CYP3A4 activity}

Baseline CYP3A4 activity measured before the first control period and before the second period was significantly correlated $\left(r^{2}=0.61 ; \mathrm{p}=0.002\right)$ but not statistically different ( $\mathrm{p}=0.86$; paired $t$-test). Baseline CYP3A4 activity was significantly correlated with simvastatin $\mathrm{C}_{\max }$ and $\mathrm{AUC}_{0-12}$ in control period, but showed no correlation with any pharmacokinetic parameters of simvastatin or simvastatin acid in amlodipine period. Baseline CYP3A4 activity is presented in Supplementary Table 1.

\section{Effects of CYP3A4 inhibition}

After pretreatment of amlodipine, exposure $\left(\mathrm{AUC}_{0-12}\right.$ and $\mathrm{C}_{\max }$ ) to simvastatin was increased by around $80 \%(\mathrm{p}<0.01)$ and exposure to simvastatin acid was increased by around $40 \%(\mathrm{p}<0.01)$. The $\mathrm{t}_{1 / 2}$ of simvastatin was increased by $40 \%(\mathrm{p}<0.01)$, whereas the $\mathrm{t}_{1 / 2}$ of simvastatin acid showed no significant change. Results are shown in Figure 2 and Table 2.

\section{Effects of SLCO1B1 \& $A B C B 1$ genotypes}

Exposure $\left(\mathrm{AUC}_{0-12}\right.$ and $\left.\mathrm{C}_{\max }\right)$ to simvastatin was not different between the SLCO1B1 genotypes. The $\mathrm{t}_{1 / 2}$ of simvastatin and exposure to simvastatin acid were around $40 \%$ higher in the SLCO1B1 T/C group than in the T/T group ( $<<0.05$; Table 2$)$. No pharmacokinetic parameters were significantly different between the $A B C B 1$ genotypes, other than the $\mathrm{t}_{1 / 2}$ of simvastatin, which was about $30 \%$ higher in the $A B C B 1$ TTT/TTT group than in the CGC/CGC group (Table 2). The pharmacokinetic parameters of simvastatin and simvastatin acid in each subgroup are shown in Supplementary Table 2.

\section{Interactions between SLCO1B1 \& $A B C B 1$} genotypes \& CYP3A4 inhibition

The linear-mixed model analyses showed that the SLCO1B1 and ABCB1 genetic effects, as well as the 


\begin{tabular}{|c|c|c|c|c|c|}
\hline \multirow{2}{*}{$\begin{array}{l}\text { Combined } \\
\text { genotype } \\
\text { number }\end{array}$} & \multirow{2}{*}{$\begin{array}{l}\text { SLCO1B1 } \\
\text { T521C }\end{array}$} & \multicolumn{3}{|c|}{$A B C B 1$} & \multirow{2}{*}{$\begin{array}{l}\text { Counts } \\
\text { (frequency) }\end{array}$} \\
\hline & & C1236T & G2677T(A) & С3435T & \\
\hline 1 & $\mathrm{~T} / \mathrm{T}$ & $\mathrm{C} / \mathrm{T}$ & $\mathrm{G} / \mathrm{T}$ & $\mathrm{C} / \mathrm{T}$ & $58(11.9 \%)$ \\
\hline 2 & $\mathrm{~T} / \mathrm{T}$ & $T / T$ & $\mathrm{G} / \mathrm{T}$ & $\mathrm{C} / \mathrm{T}$ & 45 (9.2\%) \\
\hline 3 & $\mathrm{~T} / \mathrm{T}$ & $T / T$ & $\mathrm{~T} / \mathrm{T}$ & $T / T$ & $41(8.4 \%)$ \\
\hline 4 & $\mathrm{~T} / \mathrm{T}$ & $\mathrm{C} / \mathrm{T}$ & $\mathrm{G} / \mathrm{G}$ & $\mathrm{C} / \mathrm{C}$ & $40(8.2 \%)$ \\
\hline 5 & $\mathrm{~T} / \mathrm{T}$ & $\mathrm{C} / \mathrm{T}$ & $\mathrm{A} / \mathrm{T}$ & $\mathrm{C} / \mathrm{T}$ & $35(7.2 \%)$ \\
\hline 6 & $\mathrm{~T} / \mathrm{T}$ & $\mathrm{C} / \mathrm{C}$ & $\mathrm{G} / \mathrm{A}$ or $\mathrm{G} / \mathrm{T}$ & $\mathrm{C} / \mathrm{C}$ & $32(6.5 \%)$ \\
\hline 7 & $\mathrm{~T} / \mathrm{T}$ & $\mathrm{C} / \mathrm{T}$ & $\mathrm{G} / \mathrm{A}$ & $\mathrm{C} / \mathrm{C}$ & $24(4.9 \%)$ \\
\hline 8 & $\mathrm{~T} / \mathrm{T}$ & $\mathrm{C} / \mathrm{C}$ & $\mathrm{G} / \mathrm{G}$ & $\mathrm{C} / \mathrm{C}$ & $18(3.7 \%)$ \\
\hline 9 & $\mathrm{~T} / \mathrm{C}$ & $\mathrm{C} / \mathrm{T}$ & $\mathrm{G} / \mathrm{T}$ & $\mathrm{C} / \mathrm{T}$ & $18(3.7 \%)$ \\
\hline 10 & $\mathrm{~T} / \mathrm{T}$ & $T / T$ & $\mathrm{G} / \mathrm{G}$ & $\mathrm{C} / \mathrm{C}$ & $17(3.5 \%)$ \\
\hline 11 & $\mathrm{~T} / \mathrm{C}$ & $\mathrm{C} / \mathrm{T}$ & $\mathrm{A} / \mathrm{T}$ & $\mathrm{C} / \mathrm{T}$ & $17(3.5 \%)$ \\
\hline 12 & $\mathrm{~T} / \mathrm{C}$ & $T / T$ & $\mathrm{G} / \mathrm{T}$ & $\mathrm{C} / \mathrm{T}$ & $14(2.9 \%)$ \\
\hline 13 & $\mathrm{~T} / \mathrm{T}$ & $\mathrm{T} / \mathrm{T}$ & $\mathrm{T} / \mathrm{T}$ & $\mathrm{C} / \mathrm{T}$ & $12(2.5 \%)$ \\
\hline 14 & $\mathrm{~T} / \mathrm{C}$ & $\mathrm{T} / \mathrm{T}$ & $\mathrm{T} / \mathrm{T}$ & $\mathrm{T} / \mathrm{T}$ & $11(2.2 \%)$ \\
\hline 15 & $\mathrm{~T} / \mathrm{C}$ & $\mathrm{C} / \mathrm{T}$ & $\mathrm{G} / \mathrm{G}$ & $\mathrm{C} / \mathrm{C}$ & $9(1.8 \%)$ \\
\hline 16 & $\mathrm{~T} / \mathrm{T}$ & $\mathrm{C} / \mathrm{C}$ & $A / A$ & $\mathrm{C} / \mathrm{C}$ & $8(1.6 \%)$ \\
\hline 17 & $\mathrm{~T} / \mathrm{T}$ & $\mathrm{C} / \mathrm{T}$ & $\mathrm{A} / \mathrm{A}$ or $\mathrm{A} / \mathrm{T}$ & $\mathrm{C} / \mathrm{C}$ & $8(1.6 \%)$ \\
\hline 18 & $\mathrm{~T} / \mathrm{C}$ & $\mathrm{C} / \mathrm{C}$ & $\mathrm{G} / \mathrm{G}$ & $\mathrm{C} / \mathrm{C}$ & $8(1.6 \%)$ \\
\hline 19 & $\mathrm{~T} / \mathrm{C}$ & $\mathrm{C} / \mathrm{C}$ & $\mathrm{G} / \mathrm{A}$ & $\mathrm{C} / \mathrm{C}$ & $8(1.6 \%)$ \\
\hline 20 & $\mathrm{~T} / \mathrm{C}$ & $\mathrm{C} / \mathrm{T}$ & $\mathrm{G} / \mathrm{A}$ & $\mathrm{C} / \mathrm{C}$ & $6(1.2 \%)$ \\
\hline 21 & $\mathrm{~T} / \mathrm{T}$ & $\mathrm{C} / \mathrm{C}$ & $\mathrm{G} / \mathrm{A}$ or $\mathrm{G} / \mathrm{T}$ & $\mathrm{C} / \mathrm{T}$ & $5(1.0 \%)$ \\
\hline 22 & $\mathrm{~T} / \mathrm{T}$ & $\mathrm{C} / \mathrm{T}$ & $\mathrm{G} / \mathrm{T}$ & $T / T$ & $5(1.0 \%)$ \\
\hline 23 & $\mathrm{~T} / \mathrm{C}$ & $T / T$ & $\mathrm{G} / \mathrm{G}$ & $\mathrm{C} / \mathrm{C}$ & $5(1.0 \%)$ \\
\hline $24-49$ & All the others & & & & $45(9.2 \%)$ \\
\hline Total & & & & & $489(100 \%)$ \\
\hline \multicolumn{6}{|c|}{ Allele frequencies } \\
\hline & $\mathrm{T}(87 \%)$ & $C(42 \%)$ & $\mathrm{G}(47 \%)^{\dagger}$ & $C(63 \%)$ & \\
\hline & $C(13 \%)$ & $\mathrm{T}(58 \%)$ & $\mathrm{T}(37 \%)$ & $\mathrm{T}(37 \%)$ & \\
\hline \multicolumn{6}{|c|}{ Genotype frequencies } \\
\hline & $\mathrm{T} / \mathrm{T}(1 \%)$ & C/C (18\%) & G/G (22\%) & $\mathrm{C} / \mathrm{C}(40 \%)$ & \\
\hline & $\mathrm{T} / \mathrm{C}(23 \%)$ & $\mathrm{C} / \mathrm{T}(49 \%)$ & G/T (32\%) & $\mathrm{C} / \mathrm{T}(45 \%)$ & \\
\hline & $\mathrm{C} / \mathrm{C}(76 \%)$ & $\mathrm{T} / \mathrm{T}(33 \%)$ & $\mathrm{T} / \mathrm{T}(14 \%)$ & $\mathrm{T} / \mathrm{T}(14 \%)$ & \\
\hline
\end{tabular}

CYP3A4 inhibitory effect, were independent from each other and no significant interaction was detected. The additive effects of two significant factors, the SLCO1B1 genotype and CYP3A4 inhibition, on the exposure of simvastatin acid were compared between two extreme conditions: SLCO1B1 c521T/T in control period versus SLCO1B1 c521T/C in amlodipine period, the $\mathrm{C}_{\max }$ and $\mathrm{AUC}_{0-12}$ of simvastatin acid were around $90 \%$ higher in the latter than in the former (Figure 3).

\section{Discussion}

In this study, we evaluated the pharmacokinetic characteristics of simvastatin and simvastatin acid in healthy volunteers, with the presence of two established risk factors (SLCO1B1 genetic mutation and 


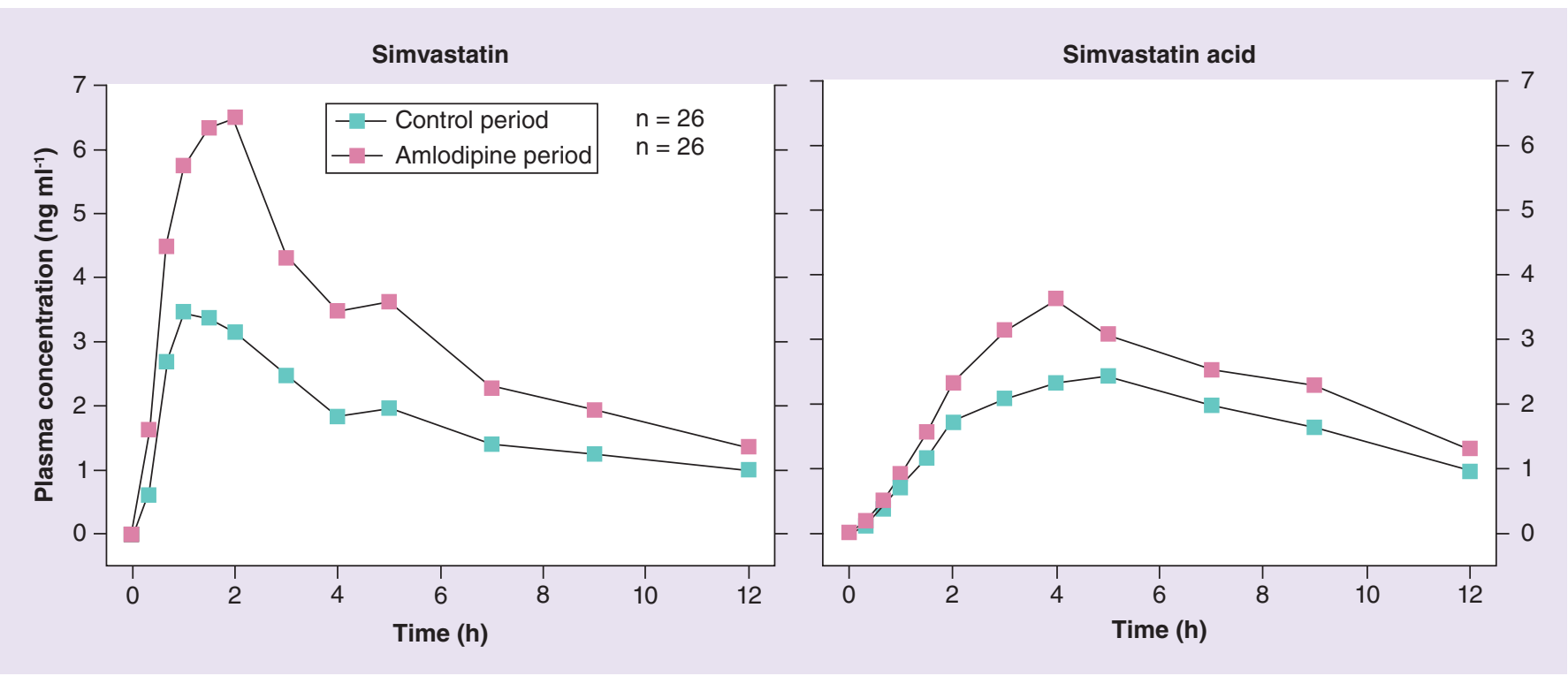

Figure 2. Mean concentration-time curves of simvastatin and simvastatin acid following administration of a single oral dose of $40 \mathrm{mg}$ simvastatin, displayed by control period (hollow) and amlodipine pretreatment (5 mg/day for 4 days) period (solid).

CYP3A4 inhibition) and one risk factor with conflicting reports ( $A B C B 1$ genetic mutation) of simvastatininduced myopathy. This study provides an insight into the general pharmacokinetic mechanisms behind simvastatin-induced myopathy related to various factors.

The frequencies of the SLCO1B1 c.521C allele (13.0\%) and the $A B C B 1$ c.1236T-2677T-3435T haplotype $(33 \%)$ observed in our study were similar to those previously reported $[22,23]$. Despite the sample sizes being unbalanced between the two genes (i.e., the number of SLCO1B1 T/T vs T/C = 16:10; $A B C B 1$ CGC/CGC vs TTT/TTT = 13:13), their effects can be measured and compared using a linear-mixed model [24]. In addition, baseline CYP3A4 activity measurement ruled out possible false genetic relationships caused by unbalanced CYP3A4 activity between genotypes.

The effects of CYP3A4 inhibitors on the pharmacokinetics of simvastatin have been previously well characterized. Co-administration of simvastatin with strong inhibitors of CYP3A4 (such as itraconazole, clarithromycin, grapefruit juice, among others) is contraindicated. On the contrary, co-administration of simvastatin and CYP3A4 weak inhibitors is very common in the clinical setting. To minimize the risk of adverse effects, we selected a low-dose $(5 \mathrm{mg})$, shortterm (4 day) pretreatment regimen of weak CYP3A4 inhibitor amlodipine to produce drug interactions. In our study, amlodipine increased the exposure $\left(\mathrm{AUC}_{0-12}\right.$

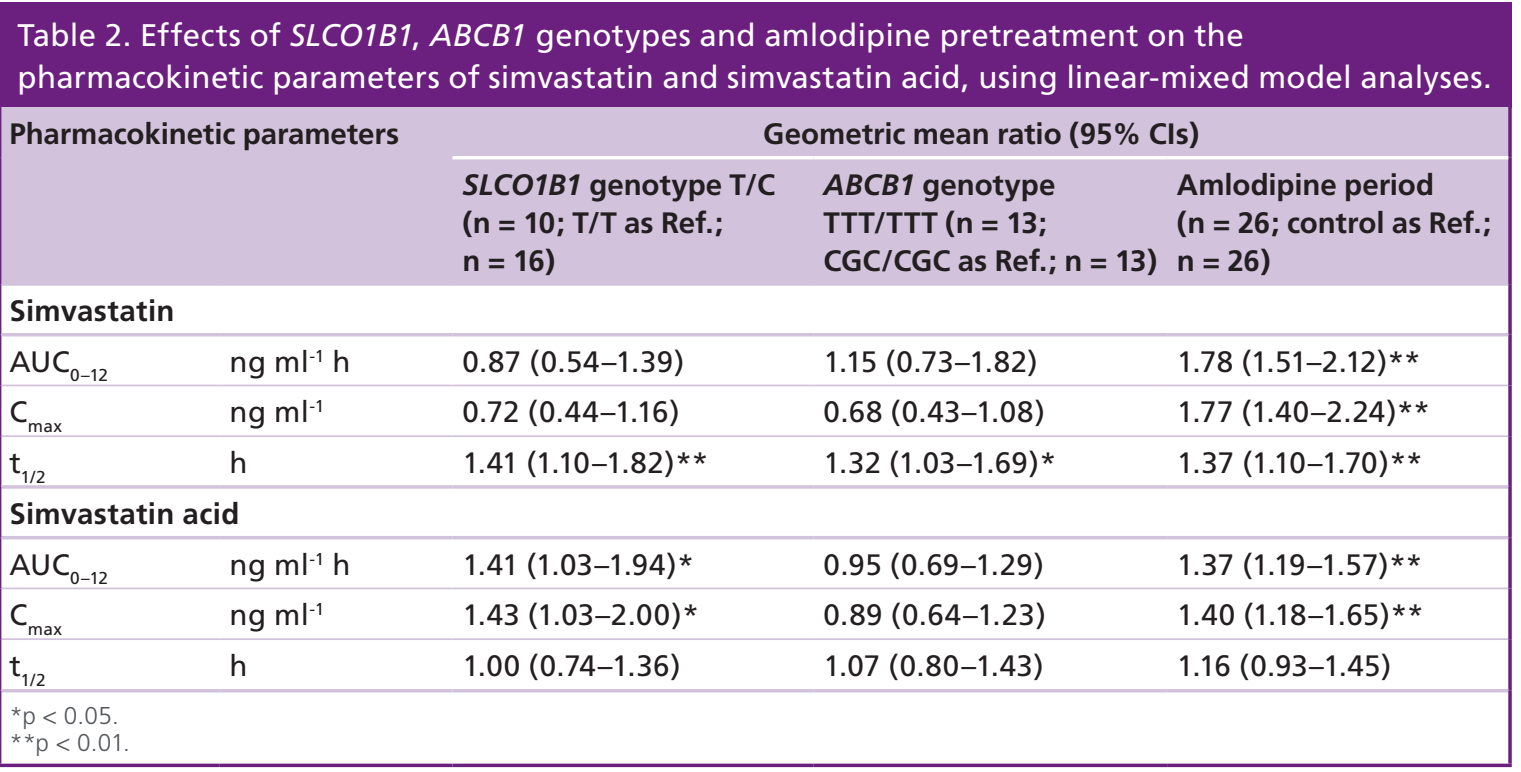



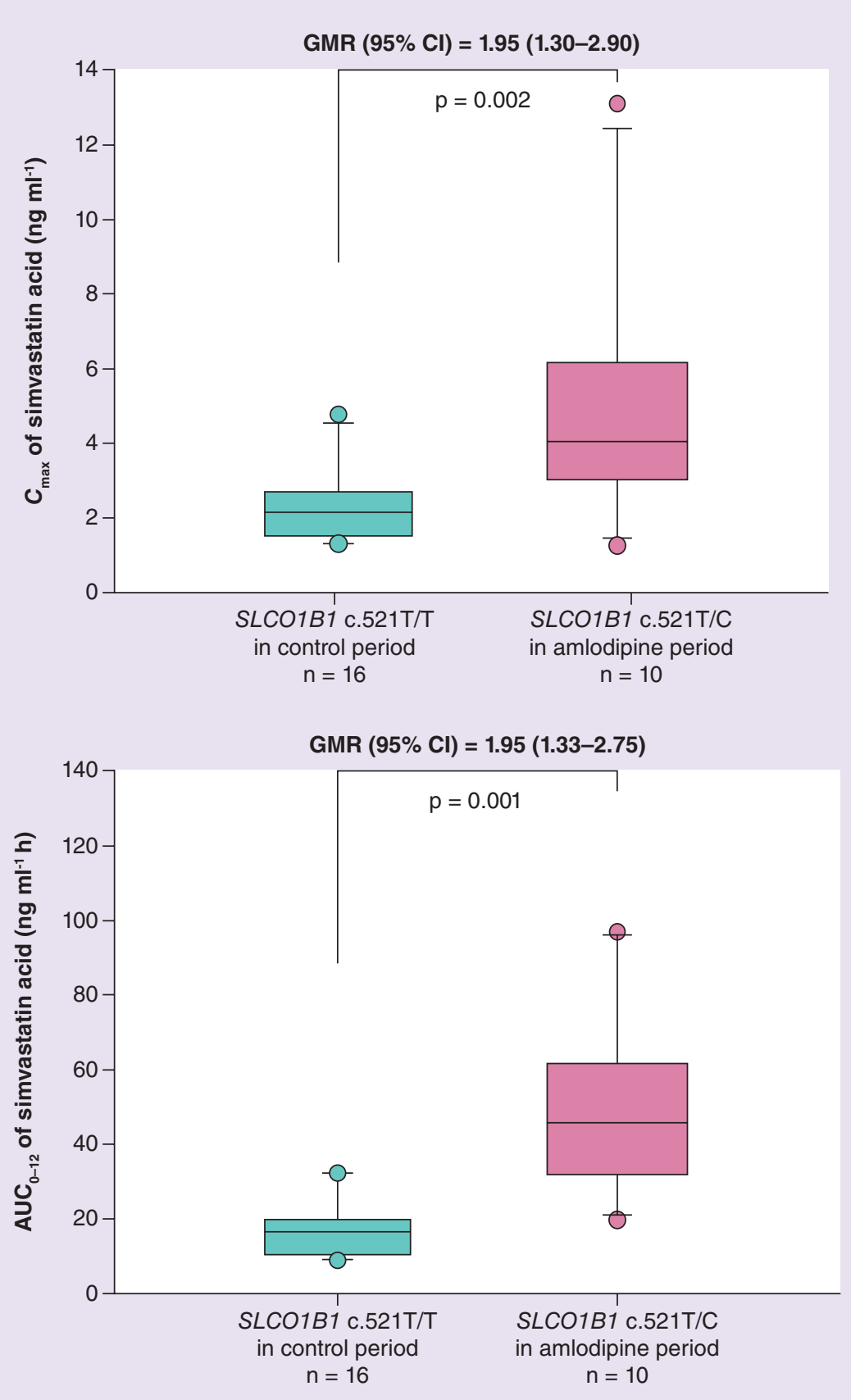

Figure 3. Box plots of exposure $\left(C_{\max }\right.$ and $\left.A U C_{0-12}\right)$ of simvastatin acid, compared between subjects of SLCO1B1 C.521T/T genotype in control period (white box) and subjects of SLCO1B1 C.521T/C genotype in amlodipine period (gray box), following administration of a single oral dose of $\mathbf{4 0} \mathbf{~ m g}$ of simvastatin. The black lines across each box represent the median. The bottom and the top edge represent the first and the third quartile, respectively. The horizontal lines connected to the whiskers denote the 1.5-times interquartile range. The circles indicate outliers from the 1.5-times interquartile range. The $p$-values were obtained from independent samples $t$-test. GMR and $95 \% \mathrm{Cl}$ were used to indicate the folds of difference between the two compared groups.

GMR: Geometric mean ratio.

and $\mathrm{C}_{\max }$ ) and $\mathrm{t}_{1 / 2}$ of simvastatin by around 80 and $40 \%$, respectively, which is in agreement with previous studies $[25,26]$. We estimate that about half of the $80 \%$ increased exposure of simvastatin can be attributed to decreased clearance because of the inhibition of hepatic CYP3A4 (indicated by the $40 \%$ increased $\mathrm{t}_{1 / 2}$ ). The remaining $40 \%$ increase of exposure is likely due to a lowered first pass elimination following the inhibition of intestinal CYP3A4. Despite simvastatin acid being a CYP3A4 substrate [27], in our study we 
only observed a $40 \%$ increase in its exposure but no change in its $\mathrm{t}_{1 / 2}$ after pretreatment of amlodipine. The different effects of CYP3A4 inhibition on simvastatin and simvastatin acid are likely because simvastatin rapidly enters the liver cells via passive diffusion and is extensively metabolized by the CYP3A4 enzyme, but the entering of simvastatin acid is mainly subject to OATP1B1 transport activity and hence its clearance is less likely to be influenced by CYP3A4 inhibition.

Our study, together with previous reports, showed that the SLCO1B1 c.521T>C variant only increased the exposure to simvastatin acid, but not simvastatin $[6,15]$. In addition, the relationship between the SLCO1B1 c.521T>C variant and simvastatin-induced myopathy has been well established at different dosage levels (ranging from 30 to $80 \mathrm{mg} /$ day), the relative risk of one copy variant is around 3 [7-9]. The established association resulted in the Clinical Pharmacogenetics Implementation Consortium Guideline which recommends a lower dose of simvastatin for patients carrying the variant [2]. While an increased exposure to simvastatin acid (but not simvastatin) may appear to be the key pharmacokinetic mechanism behind the myopathy among the SLCO1B1 c.521T >C carriers, less than one-fifth of these carriers will go on to develop this adverse effect [9] which suggests the presence of other nonpharmacokinetic contributing factors. A recent in vitro study suggests that decreased body fluid $\mathrm{pH}$ may play an important role in myotoxicity of simvastatin and simvastatin acid, particularly at higher drug concentrations [28], such are the cases in SLCO1B1 c.521T>C carriers and patients taking CYP3A4 inhibitors. It is known that diseases causing metabolic acidosis, such as diabetes and renal impairment are risk factors for simvastatin-inducedrhabdomyolysis [29]. A few documented cases of simvastatin-induced rhabdomyolysis reported incidences of metabolic acidosis [30-32]. Future studies in patients are needed to investigate the relationship between the SLCO1B1 genotype, CYP3A4 inhibition and other nonpharmacokinetic contributing factors, such as blood $\mathrm{pH}$ value, on simvastatin-induced myopathy.

To date, SLCO1B1 genotyping is not routinely performed because cost-effectiveness has not been established. To investigate the cost-effectiveness, it would be prudent to start from patients who are most likely to benefit from the SLCO1B1 genotyping, for instance, simvastatin users who are co-administered CYP3A4 inhibitors. In our study, amlodipine pretreatment and the SLCO1B1 c.521T>C variant (one copy) showed similar effects on the exposure of simvastatin acid, they both increased the exposure of simvastatin acid by around $40 \%$ and subjects with the two risk factors showed around $90 \%$ higher exposure of simvastatin acid, compared with those without. We estimate that patients with both risk factors are likely to have a much higher chance of developing myopathy. In addition, it is worth noting that both the FDA and the UK Medicines and Healthcare products Regulatory Agency propose a $50 \%$ lower dose of simvastatin for patients who coadminister amlodipine - it is unknown how this practice will influence the clinical outcomes of simvastatin treatment, particularly in patients carrying the SLCO1B1 c.521T>C variant, who are less responsive to simvastatin $[33,34]$. In conclusion, SLCO1B1 genotyping may be critical for simvastatin users who unavoidably take CYP3A4 inhibitors such as amlodipine, in order to lower the risk of adverse effects and impaired drug efficacy. Given the current dosage recommendation needs more evidence, if genotyping results identify a patient as an SLCO1B1 c.521C carrier, changing prescription to an alternative statin (such as atorvastatin) may be preferable than lowering the simvastatin dosage.

Controversy over the roles of P-gp in the transport of simvastatin acid is long standing, arising from in vitro $[10,13,35]$ and in vivo $[11,14,15]$ studies which disagree on whether simvastatin acid is a P-gp substrate, and whether $A B C B 1$ genetic polymorphisms influence the pharmacokinetics and pharmacodynamics of simvastatin. Both of these positive and negative studies are well-cited, making the controversy more confusing. Our study and more recent studies [13-15] tend to report negative results, suggesting simvastatin acid is not subject to significant intestinal transport and $A B C B 1$ genotype does not impact the pharmacokinetics of simvastatin acid. In addition, the replicated SLCO1B1 genetic effect and CYP3A4 inhibitory effect in this study serve as a study quality control for our conclusion on the $A B C B 1$. Furthermore, a widely overlooked fact is that little simvastatin acid is present in human bile following oral administration [36,37], which rules out any significant impact of hepatic efflux transporter activity on the pharmacokinetics of simvastatin acid. Collectively, P-gp activity, as well as the genetic polymorphisms in the $A B C B 1$ gene, is unlikely to be important to the pharmacokinetics of simvastatin acid. $A B C B 1$ genotyping may have little value in optimizing simvastatin treatments.

There are several limitations in the current study. First, due to our limited sample size, it was impossible to include more genetic polymorphisms in other lessstudied genes (such as SCLO1B3, CYP2D6, among others) $[14,38]$. Second, due to the low frequency of the SLCO1B1 c.521C/C genotype in the Korean population, we did not include the c.521C/C genotype and therefore we were unable to observe the potential gene-dose effect. Our genetic polymorphism enrichment study design also made subject recruitment more challenging and, because we assumed it was unlikely to impact the results greatly, two subjects with the 
SLCO1B1 T/C and ABCB1 CGC/TGC genotype were recruited and placed into the same group as the T/C-CGC/CGC genotype.

\section{Conclusion}

Despite these limitations, we hope this study will contribute to our understanding of simvastatin-induced myopathy from a pharmacokinetic perspective. Our results indicate increased exposure to simvastatin acid as a general pharmacokinetic characteristic of two independent risk factors (the SLCO1B1 c.521T>C variant and CYP3A4 inhibition) for simvastatin-induced-myopathy. However, more studies are needed to understand the contribution of nonpharmacokinetic factors to the myotoxicity of simvastatin acid. SLCO1B1 genotyping may be particularly beneficial in simvastatin users who are co-administered CYP3A4 inhibitors, to avoid risks of myopathy. On the contrary, $A B C B 1$ genotyping may have little value in optimizing simvastatin treatments.

Financial \& competing interests disclosure

This research was supported by a grant (13181MFDS704) from the Korean Ministry of Food and Drug Safety. We also thank
L Nirta from Medispeak for her valuable support. The authors have no other relevant affiliations or financial involvement with any organization or entity with a financial interest in or financial conflict with the subject matter or materials discussed in the manuscript apart from those disclosed.

No writing assistance was utilized in the production of this manuscript.

Ethical conduct of research

The study was approved by the Institutional Review Board of the Korean National Institute of Food and Drug Safety Evaluation and carried out in accordance with the Declaration of Helsinki. A written informed consent was obtained from each study participant. The clinical trial was conducted in the Clinical Trial Center of Samsung Hospital, Seoul, Republic of Korea. The Clinical Research Information Service (CRiS), Republic of Korea (a primary registry in the WHO Registry Network) identifier is KCT0001119.

\section{Open access}

This work is licensed under the Attribution-NonCommercialNoDerivatives 4.0 Unported License. To view a copy of this license, visit http://creativecommons.org/licenses/by-nc-nd/4.0/

\section{Executive summary}

- Drug metabolizing enzyme CYP3A4 and drug transporters OATP1B1 and P-gp have been studied extensively for their associations with simvastatin's pharmacokinetics and pharmacodynamics.

- CYP3A4 inhibition and the SLCO1B1 (OATP1B1 encoding gene) C.521T>C variant are established risk factors for simvastatin-induced myopathy, whereas reports on the $A B C B 1$ ( $\mathrm{P}$-gp encoding gene) genetic mutations have been conflicting.

- This study investigated the combined effects of the SLCO1B1 C.521T>C variant and the ABCB1 C.1236C>T2677G >T-3435C > T haplotype on simvastatin's pharmacokinetics in healthy volunteers, with and without a pretreatment of a CYP3A4 inhibitor amlodipine.

- Our study showed that the SLCO1B1 c.521T>C variant caused a 40\% increase $(p<0.05)$ in the exposure of simvastatin acid (but not simvastatin).

- Amlodipine showed a similar effect on simvastatin acid as the SLCO1B1 genetic effect, but it also significantly increased the exposure of simvastatin by $80 \%(p<0.01)$.

- The $A B C B 1$ haplotype did not show significant effect on the exposure of simvastatin and simvastatin acid.

- Increased exposure of simvastatin acid is the general pharmacokinetic characteristics underlying the two established risk factors, meanwhile, contributions by other nonpharmacokinetic factors to the adverse effect are suggested.

- SLCO1B1 genotyping may be particularly beneficial in simvastatin users who are co-administered CYP3A4 inhibitors, to avoid risks of myopathy and lower efficacy.

- $A B C B 1$ genotyping may have little value in optimizing simvastatin treatments.

\section{References}

1 Mendes P, Robles PG, Mathur S. Statin-induced rhabdomyolysis: a comprehensive review of case reports. Physiother. Can. 66(2), 124-132 (2014).

2 Ramsey LB, Johnson SG, Caudle KE et al. The clinical pharmacogenetics implementation consortium guideline for SLCO1B1 and simvastatin-induced myopathy: 2014 update. Clin. Pharmacol. Ther. 96(4), 423-428 (2014).

3 Mauro VF. Clinical pharmacokinetics and practical applications of simvastatin. Clin. Pharmacokinet. 24(3), 195-202 (1993).
4 Prueksaritanont T, Gorham LM, Ma B et al. In vitro metabolism of simvastatin in humans (SBT) identification of metabolizing enzymes and effect of the drug on hepatic P450s. Drug Metab. Dispos. 25(10), 1191-1199 (1997).

5 Kameyama Y, Yamashita K, Kobayashi K, Hosokawa M, Chiba K. Functional characterization of SLCO1B1 (OATP-C) variants, SLCO1B1*5, SLCO1B1*15 and $S L C O 1 B 1^{*} 15+\mathrm{C} 1007 \mathrm{G}$, by using transient expression systems of HeLa and HEK293 cells. Pharmacogenet. Genomics 15(7), 513-522 (2005).

6 Pasanen MK, Neuvonen M, Neuvonen PJ, Niemi M. SLCO1B1 polymorphism markedly affects the 
pharmacokinetics of simvastatin acid. Pharmacogenet. Genomics 16(12), 873-879 (2006).

7 Brunham LR, Lansberg PJ, Zhang L et al. Differential effect of the rs4149056 variant in SLCO1B1 on myopathy associated with simvastatin and atorvastatin. Pharmacogenomics J. 12(3), 233-237 (2012).

8 Carr DF, O'Meara H, Jorgensen AL et al. SLCO1B1 genetic variant associated with statin-induced myopathy: a proof-ofconcept study using the clinical practice research datalink. Clin. Pharmacol. Ther. 94(6), 695-701 (2013).

9 Link E, Parish S, Armitage J et al. SLCO1B1 variants and statin-induced myopathy - a genomewide study. N. Engl. J. Med. 359(8), 789-799 (2008).

10 Hochman JH, Pudvah N, Qiu J et al. Interactions of human P-glycoprotein with simvastatin, simvastatin acid, and atorvastatin. Pharm. Res. 21(9), 1686-1691 (2004).

11 Keskitalo JE, Kurkinen KJ, Neuvoneni PJ, Niemi M. ABCB1 haplotypes differentially affect the pharmacokinetics of the acid and lactone forms of simvastatin and atorvastatin. Clin. Pharmacol. Ther. 84(4), 457-461 (2008).

12 Fiegenbaum M, Da Silveira FR, Van der Sand CR et al. The role of common variants of $A B C B 1, C Y P 3 A 4$, and $C Y P 3 A 5$ genes in lipid-lowering efficacy and safety of simvastatin treatment. Clin. Pharmacol. Ther. 78(5), 551-558 (2005).

13 Li J, Volpe DA, Wang Y et al. Use of transporter knockdown Caco-2 cells to investigate the in vitro efflux of statin drugs. Drug Metab. Dispos. 39(7), 1196-1202 (2011).

14 Choi HY, Bae KS, Cho SH et al. Impact of CYP2D6, $C Y P 3 A 5, C Y P 2 C 19, C Y P 2 A 6, S L C O 1 B 1, A B C B 1$, and $A B C G 2$ gene polymorphisms on the pharmacokinetics of simvastatin and simvastatin acid. Pharmacogenet. Genomics 25(12), 595-608 (2015).

15 Zhou Q, Ruan ZR, Jiang B, Yuan H, Zeng S. Simvastatin pharmacokinetics in healthy Chinese subjects and its relations with $C Y P 2 C 9, C Y P 3 A 5, A B C B 1, A B C G 2$ and SLCO1B1 polymorphisms. Pharmazie 68 (2), 124-128 (2013).

16 Tuchscherer RM, Nair K, Ghushchyan V, Saseen JJ. Simvastatin prescribing patterns before and after FDA dosing restrictions: a retrospective analysis of a large healthcare claims database. Am. J. Cardiovasc. Drugs 15(1), 27-34 (2015).

17 Yin OQ, Shi X, Tomlinson B, Chow MS. Interindividual and intraindividual variability of the urinary Gbetahydroxycortisol/cortisol ratio in Chinese subjects: implications of its use for evaluating CYP3A activity. J. Clin. Pharmacol. 44(12), 1412-1417 (2004).

18 Yeo KP, Lowe SL, Lim MT, Voelker JR, Burkey JL, Wise $\mathrm{SD}$. Pharmacokinetics of ruboxistaurin are significantly altered by rifampicin-mediated CYP3A4 induction. Br. J. Clin. Pharmacol. 61(2), 200-210 (2006).

19 Nozawa T, Nakajima M, Tamai I et al. Genetic polymorphisms of human organic anion transporters OATP-C (SLC21AG) and OATP-B (SLC21A9): allele frequencies in the Japanese population and functional analysis. J. Pharmacol. Exp. Ther. 302(2), 804-813 (2002).

20 Cascorbi I, Gerloff T, Johne A et al. Frequency of single nucleotide polymorphisms in the P-glycoprotein drug transporter MDR1 gene in white subjects. Clin. Pharmacol. Ther. 69(3), 169-174 (2001).

21 Tan NC, Heron SE, Scheffer IE et al. Failure to confirm association of a polymorphism in $A B C B 1$ with multidrugresistant epilepsy. Neurology 63(6), 1090-1092 (2004).

22 Namgoong $S$, Cheong HS, Kim JO et al. Comparison of genetic variations of the SLCO1B1, SLCO1B3, and SLCO2B1 genes among five ethnic groups. Environ. Toxicol. Pharmacol. 40(3), 692-697 (2015).

23 Yi SY, Hong KS, Lim HS et al. A variant 2677A allele of the MDR1 gene affects fexofenadine disposition. Clin. Pharmacol. Ther. 76(5), 418-427 (2004).

24 Cnaan A, Laird NM, Slasor P. Using the general linear mixed model to analyse unbalanced repeated measures and longitudinal data. Stat. Med. 16(20), 2349-2380 (1997).

25 Nishio S, Watanabe H, Kosuge K, Uchida S, Hayashi H, Ohashi K. Interaction between amlodipine and simvastatin in patients with hypercholesterolemia and hypertension. Hypertens. Res. 28(3), 223-227 (2005).

26 Son H, Lee D, Lim LA, Jang SB, Roh H, Park K. Development of a pharmacokinetic interaction model for coadministration of simvastatin and amlodipine. Drug Metab. Pharmacokinet. 29(2), 120-128 (2014).

27 Prueksaritanont T, Ma B, Yu N. The human hepatic metabolism of simvastatin hydroxy acid is mediated primarily by CYP3A, and not CYP2D6. Br. J. Clin. Pharmacol. 56(1), 120-124 (2003).

28 Taha DA, De Moor CH, Barrett DA et al. The role of acidbase imbalance in statin-induced myotoxicity. Transl. Res. 8 , 140-160 (2016).

29 Graham DJ, Staffa JA, Shatin D et al. Incidence of hospitalized rhabdomyolysis in patients treated with lipidlowering drugs. JAMA 292(21), 2585-2590 (2004).

30 Hare CB, Vu MP, Grunfeld C, Lampiris HW. Simvastatinnelfinavir interaction implicated in rhabdomyolysis and death. Clin. Infect. Dis. 35(10), e111-e112 (2002).

31 Bhatia V. Massive rhabdomyolysis with simvastatin precipitated by amoxicillin. J. Postgrad. Med. 50 (3), 234-235 (2004).

32 De Schryver N, Wittebole X, van den Bergh P, Haufroid V, Goffin E, Hantson P. Severe rhabdomyolysis associated with simvastatin and role of ciprofloxacin and amlodipine coadministration. Case Rep. Nephrol. 2015761393 (2015).

33 Meyer Zu Schwabedissen HE, Albers M, Baumeister SE et al. Function-impairing polymorphisms of the hepatic uptake transporter SLCO1B1 modify the therapeutic efficacy of statins in a population-based cohort. Pharmacogenet. Genomics 25(1), 8-18 (2015).

34 Dou Y, Zhu X, Wang Q, Tian X, Cheng J, Zhang E. Metaanalysis of the SLCO1B1 c.521T>C variant reveals slight influence on the lipid-lowering efficacy of statins. Ann. Lab. Med. 35(3), 329-335 (2015).

35 Chen C, Mireles RJ, Campbell SD et al. Differential interaction of 3-hydroxy-3-methylglutaryl-coa reductase inhibitors with $A B C B 1, A B C C 2$, and OATP1B1. Drug Metab. Dispos. 33(4), 537-546 (2005). 
Vickers S, Duncan CA, Vyas KP et al. In vitro and in vivo biotransformation of simvastatin, an inhibitor of HMG CoA reductase. Drug Metab. Dispos. 18(4), 476-483 (1990).

37 Cheng H, Schwartz MS, Vickers S et al. Metabolic disposition of simvastatin in patients with T-tube drainage. Drug Metab. Dispos. 22(1), 139-142 (1994).
38 Kunze A, Huwyler J, Camenisch G, Poller B. Prediction of organic anion-transporting polypeptide 1B1- and 1B3mediated hepatic uptake of statins based on transporter protein expression and activity data. Drug Metab. Dispos. 42(9), 1514-1521 (2014). 